\title{
Preparation and Characterization of Capsaicin-Collagen Sponge
}

\author{
Xin-sheng Peng ${ }^{1,2,3 \#}$, Chun-lian Guo ${ }^{1,2 \#}$, Zhi-qiang Fan ${ }^{1,2}$, Yu-ling Li $^{1,2}$, Wen-en Liu ${ }^{1,2}$, Zhong Dai ${ }^{1,2 *}$ \\ and Yan-fang Zhou ${ }^{1,2 *}$ \\ ${ }^{1}$ Biomedical innovation center, Guangdong Medical University, Dongguan, Guangdong, 523808, China \\ ${ }^{2}$ Institute of Marine Medicine, Guangdong Medical University, Zhanjiang ,524023, China \\ ${ }^{3}$ Dongguan Key Laboratory of Drug Design and Formulation Technology, Dongguan, Guangdong, 523808, China \\ *Corresponding author: Zhong Dai, Guangdong Medical University, Dongguan, China \\ Yan-fang Zhou, Guangdong Medical University, Dongguan, China
}

ARTICLE INFO

Received: 蔧 March 25, 2019

Published: May 28, 2019

Citation: Xin-sheng Peng, Chun-lian Guo, Zhi-qiang Fan, Yu-ling Li, Zhong Dai, Yan-fang Zhou. Preparation and Characterization of Capsaicin-Collagen Sponge. Biomed J Sci \& Tech Res 16(5)2019. BJSTR. MS.ID.002912.

Keywords: Capsaicin; Collagen Sponge; Porosity; Water Uptake; Degradation; Drug Release

\begin{abstract}
The objective of this study was to design a capsaicin-collagen sponge to investigate the drug release mechanism and the biocompatibility of the prepared collagen sponge. According to the orthogonal experiment design, the collagen sponge was formulated containing $5 \%$ glycerin and $0.05 \%(\mathrm{w} / \mathrm{w})$ capsaicin. The prepared capsaicin-collagen sponge was a soft scaffold and characterized by Scanning Electron Microscopy (SEM). The sponge's physical properties such as porosity, water uptake, drug release and the scaffold's degradation in vitro and in vivo were carefully observed. The sponge had a porous structure and appropriate pore sizes $(60 \sim 200 \mu \mathrm{m})$. Porosity was about $114.46 \%$ (higher than 90\%) and water uptake reached 1396\%. Drug release data indicated capsaicin released from the sponges was under non-Fick's diffusion. Capsaicin release from the sponges was dependent on two simultaneous processes: the capsaicin diffusion through the system and the matrix swelling occurring at the same time. The degradation test in vitro and in vivo demonstrated that the collagen sponge was completely biodegradable and absorbed by the rats. The properties of high porosity, excellent water uptake ability, biodegradability, and being a sustained drug delivery system proved capsaicin-collagen sponge could be an ideal scaffold for wound healing.
\end{abstract}

\section{Introduction}

The ideal objective for wound therapy is to accelerate the healing process while also preventing scarring. The use of collagen matrices in wound healing has been discussed widely in the literature because of the collagen`s natural properties. Collagen is a constituent of connective tissue and a major structural protein of any organs [1]. From inducing clotting to forming the natural tissue matrix, collagen's biodegradable properties play a vital role in the natural wound healing process. Collagen stimulates formation of fibroblasts and accelerates the migration of endothelial cells upon contact with damaged tissue [2]. Collagen sponges have the ability to absorb the excessive exudates, keeping the wound bed dry while maintaining moderate moisture [3]. These characteristics make collagen attractive in the field of wound healing.
Capsaicin (trans-8-methy-N-vanillyl-6-nonenamide) is a very interesting chemical which has been widely used in clinics to relieve a variety of painful conditions [4-6]. Emerging studies have shown that capsaicin displays potent anti-tumor activity by inducing robust apoptosis in multiple types of human cancer cells and that attracts much attention [6-8]. Liu and Zhou,et al. reported capsaicin showed special preventing and curing effects on hypertrophic scars by inhibiting the proliferation of fibroblasts and collagen synthesis, and by exhausting neuropeptides SP [9-12]. However, capsaicin`s preventive effects on hypertrophic scars have been almost neglected and sparsely reported in literature to date. Hypertrophic scars are a kind of skin fibrosis and characterized by abnormally high rates of collagen production and deposition and 
increase in levels of extracellular matrix components [13]. There are great benefits when using capsaicin in wound healing. However, the burning sensation side effect of capsaicin must be alleviated when considering clinical application. Hayman's studies have shown that compared to placebo, $54 \%$ patients using capsaicin had a skin burning sensation [14]. Generally, the side-effect prolife of capsaicin formulation was much milder than free capsaicin [6].

Considering the natural characteristics of collagen and capsaicin, collagen sponge was designed to be the carrier for capsaicin. It was hoped the use of polymers as controlled release dressings could provide an excellent means of delivering drugs to wound sites in a consistent and sustained fashion over long periods of time without the need for frequent dressing change. In this study, orthogonal design methodology was used to optimize the formulation component according to porosity, water uptake, and drug release in vitro as the indicators. After the validation tests were completed, the sponge scaffold's three-dimensional structure was observed by SEM. Porosity, water uptake, and degradation of collagen sponge were carefully studied in vivo and in vitro.

\section{Material and Methods}

\section{Material}

Collagen was isolated from fresh bovine tendon, which was collected from Yuanling Supermarket (Dongguan, china, batch no: 20140411). Capsaicin was purchased from Wuhan Hengshuo Technology Development Co. Ltd. (Wuhan, Hubei, People's Republic of China). Pepsin (1:10000) was purchased from Sigma. L-Hydroxyproline was purchased from the institution for the control of pharmaceutical and biological products of China (batch no: 111578-200201). Collagenase type I was purchased from MP Biomedical, LLC (Cat NO: 195109, Lot NO: M4197). All other reagents were of high performance liquid chromatography (HPLC) or analytical grade and used as received. Animal experiments were carried out according to the approved protocol by the Experimental Animal Committee of Guangdong Medical University, Guangdong, China.

\section{Preparation of Capsaicin-Collagen Sponge and Collagen Sponge}

Capsaicin-collagen sponge and collagen sponge was prepared according to the literature with a little amendment[15,16]. Briefly, residual proteins on the surface of the fresh bovine tendon were firstly removed in $10 \% \mathrm{NaCl}$ solutions and the tendon was cleaned three times with distilled water. Then the tendon was treated with $0.5 \mathrm{M}$ acetic acid solution (containing $0.08 \%(\mathrm{w} / \mathrm{v}$ ) pepsin) for $72 \mathrm{~h}$ under magnetic stirring in cold room $\left(4^{\circ} \mathrm{C}\right)$, the insoluble parts were filtered out. Afterwards, $0.9 \mathrm{M} \mathrm{NaCl}$ was added to the solution and kept undisturbed for $24 \mathrm{~h}$ at $4^{\circ} \mathrm{C}$ to salt out the collagen from the supernatant. The next day the suspension was centrifuged at 8000 rpm for 5 minutes at $4^{\circ} \mathrm{C}$ and the precipitate was re-solubilized in $0.5 \mathrm{M}$ acetic acid. The final content was then dialyzed against $0.1 \mathrm{M}$ acetic acid and distilled water respectively for $24 \mathrm{~h}$. According to the orthogonal experimental design (Table 1), capsaicin was dissolved in ethanol. The capsaicin ethanol solution and glycerin were added respectively into the collagen solution and then vortex-mixed to achieve a homogeneous state. Then the samples were later freezedried (FD-1-50 Vacuum freeze-drying machine, Beijing Boyikang Experimental Instrument Co., Ltd.).

Table 1: The orthogonal experiment design and results.

\begin{tabular}{|c|c|c|c|c|c|}
\hline \multirow{3}{*}{ Formulation } & \multicolumn{2}{|c|}{ Factors } & \multicolumn{3}{|c|}{ Results } \\
\hline & $\mathbf{A}$ & B & \multirow[b]{2}{*}{ Porosity (\%) } & \multirow[b]{2}{*}{ Water uptake (\%) } & \multirow[b]{2}{*}{ Water uptake (\%) } \\
\hline & $\begin{array}{c}\text { Glycerin } \\
\text { concentration }(w / w)\end{array}$ & $\begin{array}{c}\text { Capsaicin } \\
\text { concentration }(w / w)\end{array}$ & & & \\
\hline 1 & $5 \%$ & $0.025 \%$ & 114.45 & 1290.34 & 52.22 \\
\hline 2 & $5 \%$ & $0.050 \%$ & 117.51 & 1375.54 & 54.10 \\
\hline 3 & $5 \%$ & $0.075 \%$ & 108.30 & 1304.44 & 50.75 \\
\hline 4 & $2 \%$ & $0.025 \%$ & 99.97 & 1050.95 & 27.11 \\
\hline 5 & $2 \%$ & $0.050 \%$ & 103.36 & 1305.76 & 43.84 \\
\hline 6 & $2 \%$ & $0.075 \%$ & 98.29 & 1206.63 & 28.06 \\
\hline 7 & $1 \%$ & $0.025 \%$ & 94.83 & 1155.36 & 25.91 \\
\hline 8 & $1 \%$ & $0.050 \%$ & 103.86 & 1053.31 & 21.88 \\
\hline 9 & $1 \%$ & $0.075 \%$ & 90.86 & 1139.87 & 37.72 \\
\hline \multicolumn{6}{|c|}{ Porosity (\%) } \\
\hline K1 & 113.42 & 103.08 & & & \\
\hline K2 & 100.54 & 108.24 & & & \\
\hline K3 & 96.52 & 99.15 & & & \\
\hline $\mathrm{R}$ & 16.90 & 9.09 & $\mathrm{~A}>\mathrm{B}$ & $\mathrm{A}_{1} \mathrm{~B}_{2}$ & \\
\hline \multicolumn{6}{|c|}{ Water uptake (\%) } \\
\hline K1 & 1323.44 & 1165.55 & & & \\
\hline K2 & 1187.78 & 1244.87 & & & \\
\hline
\end{tabular}




\begin{tabular}{|c|c|c|c|c|c|}
\hline K3 & 1116.18 & 1216.98 & \multicolumn{1}{|c|}{$\mathrm{A}_{1} \mathrm{~B}_{2}$} & \\
\hline $\mathrm{R}$ & 207.26 & 79.32 & $\mathrm{~A}>\mathrm{B}$ & \\
\hline \multicolumn{5}{|c|}{ Drug release (\%) } & \\
\hline $\mathrm{K} 1$ & 52.36 & 35.08 & & \\
\hline $\mathrm{K} 2$ & 33.00 & 39.94 & & \\
\hline $\mathrm{K} 3$ & 28.50 & 38.84 & $\mathrm{~A}>\mathrm{B}$ & $\mathrm{A}_{1} \mathrm{~B}_{2}$ & \\
\hline
\end{tabular}

\section{Porosity Measurement}

Collagen sponge samples (size: $2 \mathrm{~cm} \times 2 \mathrm{~cm}$, weight: $\mathrm{W}_{\mathrm{s}}$ ) were put into Eppendorf Tube $\mathrm{P}$ with a volume of $10 \mathrm{ml}$ ethanol (Tube together with ethanol was weighed as $\mathrm{W}_{1}$ ) and sonicated for 30 minutes. After that, the samples were withdrawn from the tube and weighed $\left(\mathrm{W}_{2}\right)$, the residual ethanol with tube was precisely weighed $\left(\mathrm{W}_{3}\right)$. The porosity of the collagen sponge samples was calculated using the following formula:

$$
\operatorname{Porosity}(\%)=\left(W_{2}-W_{3}-W_{s}\right) /\left(W_{1}-W_{3}\right) \times 100 \%
$$

Each experiment was repeated at least three times and the values are given as mean \pm standard deviation.

\section{Water Uptake Study}

Each of the collagen sponge samples (size: $2 \mathrm{~cm} \times 2 \mathrm{~cm}$, weight: $\mathrm{W}_{0}$ ) were immersed into $20 \mathrm{ml}$ of phosphate buffer solution (PBS; $\mathrm{pH}=7.4$ ). After soaking in $\mathrm{PBS}$ solution at $37^{\circ} \mathrm{C}$ for $24 \mathrm{~h}$, the samples were withdrawn from the PBS solution. The surplus surface water was removed using filter paper and weighed $\left(\mathrm{W}_{24}\right)$. The percentage of water uptake was calculated by following formula:

Water uptake $(\%)=\left(W_{24}-W_{0}\right) / W_{0} \times 100 \%$
Where $\mathrm{W}_{24}$ is the weight of sample after soaking for $24 \mathrm{~h}$ and $\mathrm{W}_{0}$ is the original weight before the test. The values are given as mean \pm standard deviation $(n=6)$.

\section{Drug Release Test}

Capsaicin-collagen sponges were transposed to a $15 \mathrm{ml}$ tube with screw caps in which $10 \mathrm{ml}$ isotonic PBS was filled and the temperature was kept at $37^{\circ} \mathrm{C}$. The solutions were stirred with magnetic stirring bars. Aliquots of $1 \mathrm{ml}$ were taken periodically and replaced with the same volume of PBS to maintain a constant volume. The samples were centrifuged for 10 minutes at a speed of 5000rpm (TGL20MWDesktop high-speed refrigerated centrifuge Hunan Hersey instrument equipment co., LTD) and the concentration of the released capsaicin in the supernatant was determined by measuring the absorbance at $280 \mathrm{~nm}$ by a spectrophotometer (UV-6000 Ultraviolet-visible spectrophotometer, Shanghai yuanxi instrument co., LTD) on the basis of the standard curve. The mechanism of capsaicin release from the collagen sponge was determined by fitting the release rate data into the different mathematical models of Higuchi, First order, Zero order, Weibull, Hixson-Crowell, Ritger-Peppas and Neibergull equations (Tables 6).

Table 2: Analysis of variance for porosity.

\begin{tabular}{|c|c|c|c|c|c|}
\hline Source & Type III Sum of Squares & df & Mean Square & F & Sig. \\
\hline Corrected Model & 592.590 & 4 & 148.147 & 27.788 & 0.004 \\
\hline A & 467.804 & 2 & 233.902 & 11.703 & 0.002 \\
\hline B & 124.785 & 2 & 62.393 & & 0.021 \\
\hline Error & 21.325 & 4 & 5.331 & & \\
\hline
\end{tabular}

Table 3: Analysis of variance for water uptake.

\begin{tabular}{|c|c|c|c|c|c|}
\hline Source & Type III Sum of Squares & df & Mean Square & F & Sig. \\
\hline A & 66486.903 & 2 & 33243.452 & 3.969 & 0.112 \\
\hline B & 9714.559 & 2 & 4857.280 & 0.580 & 0.601 \\
\hline Error & 33502.438 & 4 & 8375.609 & & \\
\hline
\end{tabular}

Table 4: Analysis of variance for drug release.

\begin{tabular}{|c|c|c|c|c|c|}
\hline Source & Type III Sum of Squares & df & Mean Square & F & Sig. \\
\hline A & 963.783 & 2 & 481.892 & 6.914 & 0.050 \\
\hline B & 38.985 & 2 & 19.492 & 0.280 & 0.770 \\
\hline Error & 278.796 & 4 & 69.699 & & \\
\hline
\end{tabular}


Table 5: The verified results of the optimized capsaicin-collagen sponge.

\begin{tabular}{|c|c|c|}
\hline Sample Name & Porosity & Water uptake \\
\hline Capsaicin-collagen sponge & $114.46 \% \pm 0.13$ & $1396 \% \pm 0.97$ \\
\hline
\end{tabular}

Table 6: Fitting of drug release data according to various equations.

\begin{tabular}{|c|c|c|c|}
\hline \multirow{2}{*}{ Model } & \multirow{2}{*}{ Fitting Equation } & \multicolumn{2}{|c|}{ Fitting Assessment Parameters } \\
\cline { 2 - 3 } & & $\mathbf{R}^{2}$ & $\mathbf{k}$ \\
\hline Higuchi equation & $\mathrm{Q}=5.7452 \cdot \mathrm{t}^{1 / 2}-4.3795$ & 0.9917 & 5.7452 \\
\hline First-order equation & $\operatorname{In}(100-\mathrm{Q})=-0.0068 \mathrm{t}+4.5285$ & 0.9568 & -0.0068 \\
\hline Zero-order equation & $\mathrm{Q}=0.4619 \mathrm{t}+8.6658$ & 0.9107 & 0.4619 \\
\hline Weibull equation & $\operatorname{In}[(\operatorname{In} 100 /$ & 0.9883 & 0.7942 \\
\hline Hixson-crowell equation & $(100-\mathrm{Q})]=0.7942 \mathrm{t}-3.8789$ & 0.9431 & -0.0092 \\
\hline Ritger-Peppas equation & $(100-\mathrm{Q})^{1 / 3}=-0.0092 \mathrm{t}+4.5158$ & 0.9800 & 0.7138 \\
\hline Neibergull equation & $(100-\mathrm{Q} \mathrm{Q})^{1 / 2}=-0.7138 \operatorname{Int}+0.7993$ & 0.9356 & -0.0279 \\
\hline
\end{tabular}

Note: Q: Cumulative capsaicin released from collagen sponge (\%). t:time (h).

\section{In vitro Degradation Test}

In vitro degradation tests were done according to the literatures $[1,17]$. Briefly, $2 \mathrm{~cm} \times 2 \mathrm{~cm}$ sponge samples were immersed in phosphate buffered saline (PBS, pH 7.4) containing $0.2 \mathrm{mg} / \mathrm{ml}$ collagenase type I. At a predetermined time point $(24 \mathrm{~h}, 48 \mathrm{~h})$, the supernatant fraction after centrifugation was hydrolyzed with $6 \mathrm{M}$ $\mathrm{HCl}$ at $150^{\circ} \mathrm{C}$ for $0.5 \mathrm{~h}$. The content of hydroxyproline was measured with UV-vis spectrophotometer .The biodegradation degree of the scaffold is judged by the released hydroxyproline.

\section{In vivo Degradation Test}

Rats were anesthetized by intraperitoneal administration of chloral hydrate $(0.3 \mathrm{ml} / 100 \mathrm{~g}$ body weight) and received a fullthickness incision of the skin on the back. Sponges were implanted under the skin through the incision, and then the incision was closed with sutures. To evaluate the biodegradation rate of sponges, rats were euthanized at intervals from 1 to 5 weeks by an overdose of chloral hydrate. The implanted sponges were carefully resected and washed in PBS, then the withdrawn sponges were digested with 0.2 $\mathrm{mg} / \mathrm{ml}$ collagenase type I for $2 \mathrm{~h}$ to remove fibrous tissue attached to the sponge. After that the sponge was cleaned with distilled water and vacuum dried for $24 \mathrm{~h}$ before analysis. The sponge's degradation degree was determined by the change of weight after degradation. The degradation rate $(\%, w / w)$ was determined by using the following formula:

$$
\text { Degradation rate }(\%)=\left(W_{0}-W_{t}\right) / W_{0} \times 100 \%
$$

Where $\mathrm{W}_{\mathrm{t}}$ is the weight of sample at predetermined time $\mathrm{t}$ and $\mathrm{W}_{0}$ is the original weight before the test. The values are given as mean \pm standard deviation $(\mathrm{n}=3)$.

\section{Scanning Electron Microscopy (SEM) Observation}

Macroscopic images of the collagen sponge were taken by a digital camera (Canon, EOS 600D). The collagen sponges' cross sections were observed by a scanning electron microscopy (SU8020, Hitachi cold field emission scanning electron microscope, Japan). The samples' cross-sections were obtained by treating the membrane with liquid nitrogen. All of the samples were sputtered with gold before SEM observation.

\section{Statistical Analysis}

Results are reported as means \pm SD. Univariate analysis of variance was estimated by using SPSS software version 15.0 and the observed differences were statistically significant when $\mathrm{P}<$ 0.05 .

\section{Result and Discussion}

\section{Results and Analysis of Optimal Conditions for the Preparation of Sponge}

It is well known drug release kinetics can be influenced by the matrix characteristics (porosity, density) or by its degradation rate [18]. As a moisture-retaining plasticizer, glycerin can improve the material's characteristics to make it usable as an aqueous sustainedrelease material for drugs [19]. Glycerin was also documented as being used as an anti-irritant for certain concentrations of capsaicin $(0.025 \%)$ to alleviate pain [20]. That is also the main reason why the glycerin was one of the compositions in the formulation.

As shown in Table 1, glycerin concentrations had more influence than capsaicin concentrations on sponge characteristics (porosity, water uptake, drug release). The variance analysis (Tables 2 \& 3) confirms the result. The difference is significant as shown in Table 2 and Table $4(\mathrm{p}<0.05)$. The concentration of glycerin is a main factor while preparing sponges. As glycerin concentration increases, the porosity and water uptake of the sponge increases as well. Interestingly, the capsaicin release from the sponge also increases.

An ideal scaffold for skin tissue engineering should possess excellent biocompatibility, suitable microstructure such as 50 150 $\mu \mathrm{m}$ mean pore size, porosity above $90 \%$, and suitable mechanical 
property $[21,22]$. Based on the results of porosity and water uptake, concentrations of $5 \%$ glycerin and $0.05 \%$ capsaicin were selected to prepare the collagen sponge.

\section{Optimization and Validation}

Three batch samples $(0.05 \%$ capsaicin, $5 \%$ glycerin $)$ were prepared according to the item 2.2. The scaffolds properties were characterized by porosity, water uptake, drug release, and degradation test in vitro and in vivo according to the above description.

\section{Porous Structure Detection}

The porosity of the optimized scaffolds $(0.05 \%$ capsaicin, $5 \%$ glycerin) was $(114.46 \% \pm 0.13)$, which is greater than $90 \%$. In soft tissue engineering, scaffold materials should have a porous nature for nutrient and gas exchange: which benefits cell proliferation and tissue growth [23]. Similar results were reported by T Muthukumar [24]. In the early stage of wound healing, the nutrient that cells need will entirely depend on tissue fluids surrounding the wound. The ability of the scaffold to absorb water is one of the most important factors in determining the biological activity of a dermal equivalent [1]. Sara Mohajeri et al. [25] demonstrated when collagen sponges were incorporated with PP/PET fiber, the water uptake value between $800 \%$ and $2000 \%$ was conducive to the proliferation and differentiation of mesenchymal stem cells. Yang et al. [26] reported that chitosan scaffold made from chitosan/dibasic sodium phosphate solution had a water adsorption ranging from $850 \%$ to $1650 \%$, which was much greater than the porous membrane.

The optimized preparation's water uptakes were detected as $1355.48 \%, 1422.08 \%$, and $1546.07 \%$. The mean of water uptake (1396\% \pm 0.97 , Table 5) is higher than $1000 \%$ which is qualified to the requirement of the scaffolds. In addition, the hydrophilic properties of glycerine are beneficial to enhance the water uptake of sponge scaffolds. During the complex wound healing process, there are always excessive production of exudates. These exudates can inhibit wound healing because of higher levels of tissue destructive proteinase enzymes and therefore more corrosive [27]. A key characteristic of wound dressings is the removal of excess exudate while maintaining moisture at the wound bed [3]. More porous collagen sponges may provide a potential advantage to wound tissue by the adsorption of ample exudates [27] Table 5.

The porosity and water uptake characteristics showed that capsaicin-collagen sponges had a porous structure. In fact, the porous structures of the scaffolds were also demonstrated by SEM observation (Figure 1).

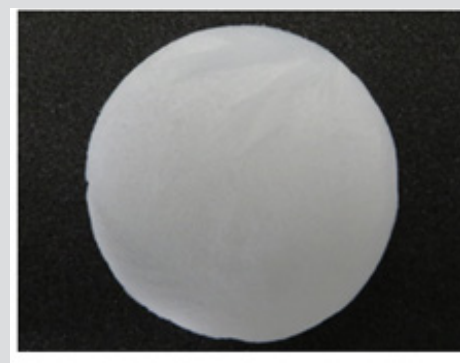

A

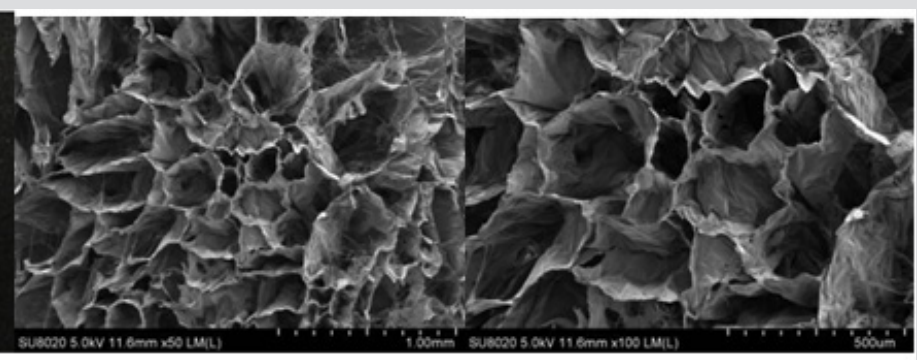

C

Figure 1: Macroscopic shape of scaffolds (a) and the SEM image from the cross-section $(b, c)$.

Figure 1(A) shows the sponge was white and soft. Many dense, little uniform pores are clearly observed under the SEM, pore size was between $60 \sim 200 \mu \mathrm{m}$ by Image Pro Plus 6.0 software. Highly porous three-dimensional structure is conducive to the rapid absorption of tissue exudates, rapid hemostasis, and promotes wound repair [29]. Pore sizes between $50 \mu \mathrm{m}$ and $150 \mu \mathrm{m}$ are found to be optimal for improved extracellular matrix production [22]. The porous nature of the collagen sponge helps in absorbing wound fluids, keeping the wound dry, and also helps supply oxygen to the wound [30].

\section{In Vitro Release Study}

Figure 2 plots the percentage of capsaicin released as a function of time from the collage sponges. After $132 \mathrm{~h}$, around $56 \%$ of capsaicin was released from the sponge. It was shown that collagen sponges could provide a sustained release system for capsaicin. Table 6 summarizes the results of fitting the release data for sponges. A linear relationship was found between capsaicin release and the square root of time $\left(\mathrm{R}^{2}>0.99\right)$ and indicated that the release is under diffusion control following Higuchi's equation, namely the capsaicin release was under diffusion control [31].

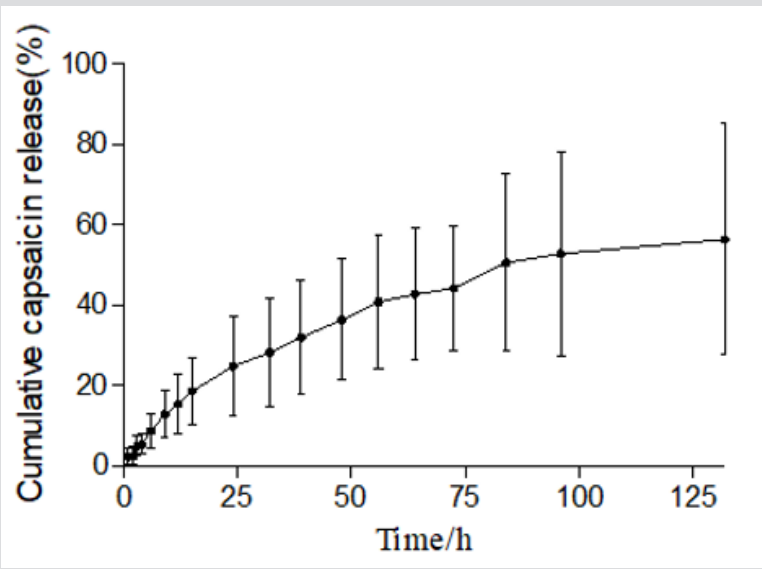

Figure 2: The cumulative capsaicin released from collagen sponge versus time $(n=3)$, 
The empirical Ritger-Peppas equation was widely used to explain the drug release mechanism [32-35] (the meaning of $\mathrm{k}$ is shown in Table 7). A value of 0.45 for $\mathrm{k}$ indicates Fickian diffusion, which is when the drug is released by the molecular diffusion through the system. A value between 0.45 and 0.89 for $\mathrm{k}$ is indicative of anomalous transport in which Fickian transport and matrix relaxation occur simultaneously.

Table 7: Explanation of $\mathrm{k}$ value for drug release mechanism.

\begin{tabular}{|c|c|}
\hline Release exponent/k & Drug release mechanism \\
\hline $\mathrm{k} \leq 0.45$ & Fickian diffusion \\
\hline $0.45<\mathrm{k}<0.89$ & Non-Fickian diffusion \\
\hline $\mathrm{k} \geq 0.89$ & Bulk erosive release \\
\hline
\end{tabular}

The diffusion exponent $(\mathrm{k}=0.7138)$ calculated by the RigerPeppas Equation is greater than 0.5 (Table 6) which indicates the release mechanism for collagen sponges is anomalous transport, and that the release of capsaicin in the collagen sponge is under non-Fick's diffusion. Capsaicin release was dependent on two simultaneous processes, the capsaicin diffusion through the system and the matrix swelling occurring at the same time. The release mechanism from sponges is similar to the drug delivery systems of the cubic phase gels and cubosomes [36,37]. On the contrary to the tortuosity of the water channels of the cubic phases, sponge matrix swelling increased the diffusion rate of capsaicin. Our previous study showed that approximately $34 \%$ of the capsaicin was released after $108 \mathrm{~h}$ from the cubic phase [36], which is much slower than that from sponges (96h, 51.79\%; 132h, 56\% ). The difference attributes to the water uptake and swelling ability of the matrix. The mean of water uptake (1396\%) of sponges is much better than that of the cubic phases (approximately 14 33\%) [38]. The huge water uptake and swelling ability provides more chances for capsaicin to diffuse from the sponge layers, resulting in faster release.

\section{In vitro and in vivo Degradation Test}

The degradation properties of a scaffold are of crucial importance in the long-term success of a tissue-engineered cell- scaffold construction. The rate of degradation may affect many cellular processes including cell growth, tissue regeneration, and host response [39]. Too fast or too slow degradation of collagen affects the healing of a wound.

In vitro degradation is usually simulated by incubation with bacterial collagenase, cathepsin, pepsin, or trypsin. Hydroxyproline as a specific amino acid being relatively constant in the proportion of collagen [29], was used as a marker for collagen metabolism [40]. Therefore, the change of hydroxyproline concentration reflects the degradation of the collagen sponge. At $24,48 \mathrm{~h}$, testing samples degraded $21.96 \%$ and $58.13 \%$ respectively.

In vitro degradation characteristics are an important index for the scaffold. However, positive correlation between in vitro and in vivo degradation rates is hard to achieve [41-43]. During the process of wound healing, absorption of exogenous collagen in vivo is a complex multi-enzyme process where deposition of newly formed collagen and remodeling of connective tissue has to be considered [44-46]. Hence, the biocompatibility and biodegradability of the scaffolds was evaluated in vivo. Table 8 showed the degradation of sponges implanted subcutaneously in vivo. As time elapsed, the weight of the reserved scaffolds in rat decreased gradually. Five weeks later, the sponges degraded eventually. Figure 3 shows the changes of the scaffolds implanted in rats at different time. By visual observation at the first week, the sponge adhered closely to the subcutaneous tissue but could be peeled off easily.

Table 8: The degradation of sponges in rats.

\begin{tabular}{|c|c|}
\hline Time/week & Capsaicin-collagen sponge (Mean \pm SD $)$ \\
\hline & Fickian diffusion \\
\hline 1 & $34.50 \% \pm 0.040$ \\
\hline 2 & $41.49 \% \pm 0.067$ \\
\hline 3 & $67.25 \% \pm 0.049$ \\
\hline 4 & $77.13 \% \pm 0.046$ \\
\hline 5 & $100 \%$ \\
\hline
\end{tabular}

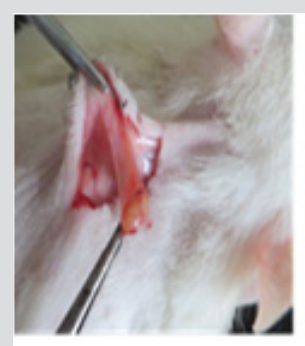

$1 \mathrm{~W}$

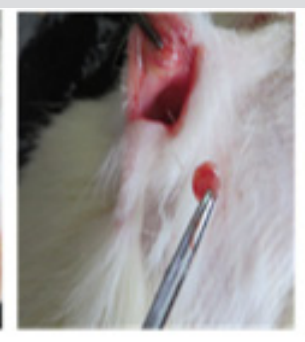

$2 \mathrm{~W}$

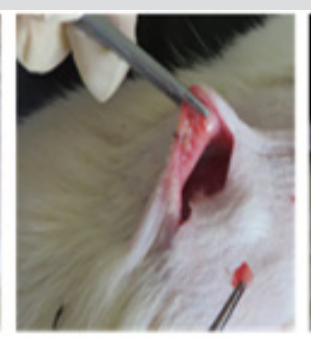

$3 \mathrm{~W}$

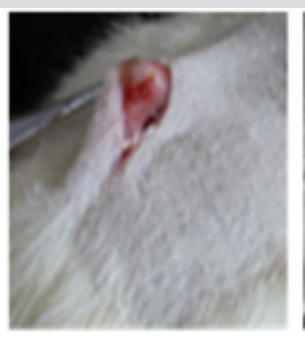

$4 \mathrm{~W}$

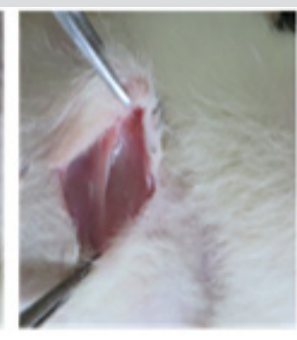

$5 \mathrm{~W}$

Figure 3: The degradation of capsaicin-collagen sponge at different weeks.

Two weeks later, the scaffold became smaller and adhered tighter to the tissue. On the fourth week, the sponge turned into small clumps, linked to the subcutaneous tissue closely, and was difficult to peel off. After five weeks the sponge had degraded completely and integrated fully with the subcutaneous tissue: no necrotic tissue and inflammatory reaction around the implant site 
was detected. During the periods of subcutaneous implantation of sponges, no abnormal activities were observed for the SD rats. The data above indicates that sponges have good biocompatibility and are safe.

\section{Conclusion}

The prepared capsaicin-collagen sponges with porous structures (porosity, 114.46\%; water uptake, 1396\%) had the potential to be beneficial in absorbing wound fluids, keeping the wound dry, and helping the oxygen supply to the wound region. Characteristics of the appropriate pore size $(60 \sim 200 \mu \mathrm{m})$ of the prepared scaffold could be conducive to the wound healing. The degradation test in vitro and in vivo demonstrated the scaffold could be completely biodegraded and absorbed by the rats which eradicates the risk of infection caused by removing the residue from the body. Drug release data indicated capsaicin release from the sponges was under diffusion control following Higuchi's equation. By studying the Ritger-Peppas equation it was determined the release mechanism for collagen sponges is anomalous transport and that the release of capsaicin from the collagen sponge is under non-Fickian's diffusion.

Capsaicin release was dependent on two simultaneous processes, the capsaicin diffusion through the system and the matrix swelling occuring at the same time, the huge water uptake and swelling ability provides the sustained and comparatively faster drug release for the capsaicin. The properties of high porosity, excellent water uptake ability, biodegradability, and sustained drug delivery system described above provides evidence that collagen sponge may be an ideal scaffold used for skin tissue engineering. Based on the innovative study, a patent was applied in China (no: ZL 201410760525.5). In the next stage, the rat skin excision model will be built and the in vivo regulation of capsaicin-collagen sponge on wound closure, angiogenesis, and collagen disposition will be evaluated in detail.

\section{Conflict of Interests}

The authors declare that they have no conflict of interests regarding the publication of this paper.

\section{Authors' Contribution}

Xin-sheng Peng and Chun-lian Guo contributed equally to this work.

\section{Acknowledgment}

The authors gratefully acknowledge the financial support of Science \& Technology Planning Project of Guangdong Province, China (No: 2015A020214020). Also, would like to give a special thanks to Alexander Van Fleet for editing.

\section{References}

1. Liu YV, Ma L, Gao CY (2012) Facile fabrication of the glutaraldehyde crosslinked collagen/chitosan porous scaffold for skin tissue engineering. Mater Sci and Eng 32 (8): 2361-2366.
2. Mian M, Beghe F, Mian E (1992) Collagen as a pharmacological approach in wound healing. Int J Tissue React 14: 1-9.

3. Boateng JS, Matthews KH, Stevens HN, Eccleston GM (2008) Wound healing dressings and drug delivery systems: A review. J Pharm Sci vol 97(8): 2892-2923.

4. Hautkappe M, Roizen MF, Toledano A, Roth S, Jeffries JA, et al. (1998) Review of the effectiveness of capsaicin for painful cutaneous disorders and neural dysfunction. Clin J Pain 14(2): 97-106.

5. Bode AM, Dong ZG (2011) The two faces of capsaicin. Cancer Res 71(8): 2809-2814.

6. Rollyson WD, Stover CA, Brown KC, Perry HE, Stevenson CD, et al. (2014) Bioavailability of capsaicin and its implications for drug delivery. J Controlled Release 196: 96-105.

7. Aggarwal BB, Kunnumakkara AB, Harikumar KB, Tharakan ST, Sung B, et al. (2008) Potential of spice-derived phytochemicals for cancer prevention. Planta Med 74(13): 1560-1569.

8. Lau JK, Brown KC, Dom AM, Witte TR, Thornhill BA, et al. (2014) Capsaicin induces apoptosis in human small cell lung cancer via the TRPV6 receptor and the calpain pathway. Apoptosis19(8): 1190-1201.

9. Liu CL, Xu H, Zhao XF (2004) Effect of capsaicin on the prohferation and collagen synthesis of hypertrophic scar-derived fibroblast. Chin J Clin Rehabil 8(5): 908-909.

10. Liu CL, Li A, Zhao XF, Dai MX (2000) A clinical study of capsaicin drug sheet on preventing and treating hypertrophic scar. Modern Rehabil 4(7): 1032-1033.

11. Lu GX, Zhou YX, Song LY, Peng XS, Zhou ZK et al. (2018) The inhibitive effect of capsaicin cubic liquid crystal nanoparticles on scar formation. Guangdong Medical Journal 39(17): 2549-2553. http://mall.cnki.net/ magazine/Article/GAYX201817001.htm.

12. Zhou YX, Peng XS, Hou G, Li JB, Zhang H et al. (2019) Inhibitory effect of capsaicin on fibroblast proliferation and its molecular mechanism. Chinese Journal of Tissue Engineering Research 23(7):1018-1022. http://www.cnki.com.cn/Article/CJFDTotal-XDKF201907009.htm.

13. Zhu HY, Li C, Zheng Z, Zhou Q, Guan H, et al. (2015) Peroxisome proliferator-activated receptor- $\gamma$ (PPAR- $\gamma$ ) agonist inhibits collagen synthesis in human hypertrophic scar fibroblasts by targeting Smad3 via miR-145. Biochem Biophys Res Commun 459(1): 49-53.

14. Hayman M, Kam PC A (2008) Capsaicin: A review of its pharmacology and clinical applications. Current Anaesthesia \& Critical Care 19(5): 338-343.

15. Guo CL, Chen HY, Cui BL, Chen YH, Zhou YF, et al. (2015) Development of a HPLC Method for the Quantitative Determination of Capsaicin in collagen sponge. Int J Anal Chem, p. 6.

16. Liu, WE,Zhou, YF,Fan, ZQLi, YL,Gan, B et al. (2019) Optimization of Purification Process of Collagen Type I. Fine Chemicals 36(5):850 855,874. http://mall.cnki.net/magazine/article/JXHG201905010.htm.

17. Mei L, Hu D, Ma J, Wang X, Yang Y, et al. (2012) Preparation, characterization and evaluation of chitosan macroporous for potential application in skin tissue engineering. Int J Biol Macromol 51(5): 992 997. https://doi.org/10.1016/j.ijbiomac.2012.08.004.

18. Umar S, Uma Kr, Sarwar AH MG, Khan A, Ahmad N, et al. (2014) Boswellia serrata extract attenuates inflammatory mediators and oxidative stress in collagen induced arthritis. Phytomedicine 21(6): 847-856.

19. Nishida A, Yamada M, Kanazawa T, Takashima Y, Ouchi K, et al. (2010) Use of silk protein, sericin, as a sustained-release material in the form of a gel, sponge and film. Chem Pharm Bull 58(11): 1480-1486.

20. Kamkaen N, Samee W, Nimkulrut S, Managit C, Leerungnavarat O, et al. (2010) Development of new formulation and study on release of capsaicin from transdermal patch. J Health Res 24(4): 151-154.

21. Chen G, Ushida T, Tateishi T (2002) Scaffold design for tissue engineering Macromol Biosci 2(2): 67-77. 
22. Ma L, Gao C, Mao Z, Zhou J, Shen JC, et al. (2003) Collagen/chitosan porous scaffolds with improved biostability for skin tissue engineering. Biomaterials 24(26): 4833-4841.

23. Bhattarai, SR,Bhattarai, N,Yi, HK,Hwang, PH,Cha, DI et al. (2004) Novel biodegradable electrospun membrane: scaffold for tissue engineering. Biomaterials 25(13):2595-2602. https://doi.org/10.1016/j.biomaterials.2003.09.043.

24. Muthukumar, T,Prabu, P,Ghosh, K,Sastry, TP (2014) Fish scale collagen sponge incorporated with Macrotyloma uniflorum plant extract as a possible wound/burn dressing material. Colloids and Surfaces B: Biointerfaces 113:207-212. https://doi.org/10.1016/j. colsurfb.2013.09.019.

25. Sara Mohajeri, Hosseinkhani H, Ebrahimi NG, Nikfarjam L, Soleimani M, et al. (2010) Proliferation and differentiation of mesenchymal stem cell on collagen sponge reinforced with polypropylene/polyethylene terephthalate blend fibers. Tissue Eng Part A. 16(12): 3821-3830.

26. Yang B, Li XY, Shi S, Kong XY, Guo G, et al. (2010) Preparation and characterization of a novel chitosan scaffold. Carbohydr Polym 80(3): 860-865.

27. Chen WYJ, Rogers AA, Lydon MJ (1992) Characterization of biologic properties of wound fluid collected during early stages of wound healing. J Ivest Dermatol 99(5): 559-564.

28. Chen F, Tian M, Zhang DM, Wang JY, Wang QG, et al. (2012) Preparation and characterization of oxidized alginate covalently cross-linked galactosylated chitosan scaffold for liver tissue engineering. Mater Sci Eng C 32(2): 310-320.

29. Friess W(1998) Collagen-Biomaterial for drug delivery. Eur J Pharm Biopharm 45(2): 113-136.

30. Natarajan N, Shashirekha V, Noorjahan SE, Rameshkumar M, Rose C, et al. (2005) Fibrin-chitosan-gelatin composite film: preparation and characterization. J Macromol Sci A 42(7): 945-953.

31. Tanaka N, Imai K, Okimoto K, Ueda S, Tokunaga YJ, et al. (2005) Development of novel sustained-release system, DisintegrationControlled Matrix Tablet (DCMT) with solid dispersion granules of nilvadipine. J Control Release 108(2-3): 386-395.

32. Pillay V, Fassihi R (1999) In vitro release modulation from crosslinked pellets for site-specific drug delivery to the gastrointestinal tract: I. Comparison of $\mathrm{pH}$-responsive drug release and associated kinetics. J Control Release 59(2): 229-242.

33. Ritger PL, Peppas NA (1987) A simple equation for description of solute release I. Fickian and non-fickian release from non-swellable devices in the form of slabs, spheres, cylinders or discs. J Control Release 5(1): 2336.

\section{ISSN: 2574-1241}

DOI: 10.26717/BJSTR.2019.16.002912

Zhong Dai, Yan-fang Zhou. Biomed J Sci \& Tech Res

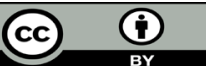

This work is licensed under Creative

Commons Attribution 4.0 License

Submission Link: https://biomedres.us/submit-manuscript.php
34. RitgerP, LPeppas NA (1987) A simple equation for description of solute release II. Fickian and anomalous release from swellable devices. Journal of Controlled Release 5(1):37-42. https://doi.org/10.1016/01683659(87)90035-6.

35. Ferrero C, Massuelle D, Doelker E (2010) Towards elucidation of the drug release mechanism from compressed hydrophilic matrices made of cellulose ethers. II. Evaluation of a possible swelling-controlled drug release mechanism using dimensionless analysis. J Control Release 141(2): 223-233.

36. Peng XS, Wen XG, Pan X, Wang RC, Chen B, et al. (2010) Design and in vitro evaluation of capsaicin transdermal controlled release cubic phase gels. AAPS Pharm Sci Tech 11(3): 1405-1410.

37. Peng XS, Zhou YF, Han K, Qin LZ, Dian LH, et al. (2015) Characterization of cubosomes as a targeted and sustained transdermal delivery system for capsaicin. Drug Des Devel Ther 9: 4209-4218.

38. Barauskas J, Landh T (2003) Phase behavior of the phytantriol/water system. Langmuir 19(23): 9562-9565.

39. Liao SS, Cui FZ (2004) In vitro and in vivo degradation of mineralized collagen-based composite scaffold: Nanohydroxyapatite/collagen/poly (L-lactide). Tissue Eng 10(1-2): 73-80.

40. Laurent GJ (1987) Dynamic state of collagen: pathways of collagen degradation in vivo and their possible role in regulation of collagen mass. Am J Physiol Cell Physiol 252(1): C1-C9.

41. Diamond AM, Gorham SD, Etherington DJ, Robertson JG, Light ND (1991) The effect of modification on the susceptibility of collagen to proteolysis: I. Chemical modification of amino acid side chains. Matrix 11(5): 321329.

42. Yannas IV, Burke JF, Huang C, Gordon PL (1975) Correlation of in vivo collagen degradation rate with in vitro measurements. J Biomed Mater Res 9(6): 623-628.

43. Okada T, Hayashi T, Ikada Y (1992) Degradation of collagen suture in vitro and in vivo. Biomaterials 13(7): 448-454.

44. Romanos GE, Hotz ST K, Schröter-Kermani C, Strub JR (1995) Extracellular matrix interactions during the in vivo degradation of collagen membranes in the rat skin: Immunohistochemical distribution of collagen types IV, V, and VI. J Biomed Mater Res 29(9): 1121-1127.

45. Van Wachem PB, Van Luyn MJA, Nieuwenhuis P, Koerten HK, Olde Damink L, et al. (1991) In vivo degradation of processed dermal sheep collagen evaluated with transmission electron microscopy. Biomaterials 12(2): 215-223.

46. Oliver RF, Barker H, Cooke A, Grant RA (1982) Dermal collagen implants. Biomaterials 3(1): 38-40.

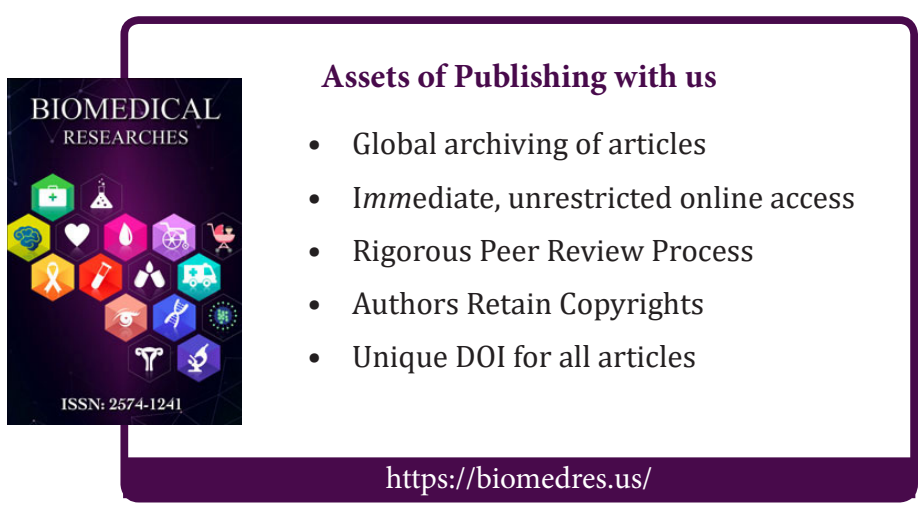

Copyright@ Zhong Dai, Yan-fang Zhou | Biomed J Sci \& Tech Res| BJSTR. MS.ID.002912. 